\title{
Imaging the Velocity Structure of Rayleigh Wave in Sulawesi Island Using Ambient Noise Tomography
}

\author{
Azwar Panshori ${ }^{1}$, Agustya Adi Martha ${ }^{2}$ and Sukir Maryanto ${ }^{3 *}$ \\ ${ }^{1}$ Magister Program, Department of Physics, University of Brawijaya, \\ Malang, East Java, Indonesia \\ ${ }^{2}$ Meteorological, Climatological and Geophysical Agency (BMKG), \\ Jakarta, Indonesia \\ ${ }^{3}$ Brawijaya Volcano and Geothermal Reserach Centre (Bravo GRC), University of Brawijaya \\ Malang, East Java, Indonesia
}

\begin{abstract}
Ambient Noise Tomography (ANT) had been applied to describe the Rayleigh wave group velocity model in the crust part of Sulawesi Island. The research data were vertical component waveform data from July 2016 to December 2017 of 25 INA TEWS BMKG network seismograph in Sulawesi Island. In general, the steps of conducting research are divided into several parts, namely single data preparation, crosscorrelation and stacking, cross-correlogram analysis, measurement of dispersion curves, velocity tomography and the last is the interpretation of research results. The estimated travel time of the Rayleigh wave group for both $5 \mathrm{~s}$ and $12 \mathrm{~s}$ periods was obtained from the time delay of the cross-correlation result. The tomography process was conducted by using FMST v1.1 where forward and inverse modeling was performed iteratively. The modeling result for the period 5 s showed that the distribution of negative anomalies corresponded to volcanoes and Inter-Volcano plains which were Quarterold. For the period $12 \mathrm{~s}$, the east arm of Sulawesi Island had a lower velocity anomaly than around other regions on the Sulawesi Island. This indicated that the tectonic activity and geological condition of Sulawesi Island was complex.
\end{abstract}

Key Words: Tomography, Ambient Noise, Cross-Correlation, Rayleigh Wave, Sulawesi Island.

\section{INTRODUCTION}

Sulawesi Island is one of the Islands in Indonesia with high seismicity and complex geological phenomena. This can be seen from the geometry of Sulawesi Island which resembles the letter K. This complexity is caused by the location of Sulawesi Island and its surroundings which are at the confluence of three large plates namely the Eurasian Plate which moves towards the South-Southeast, the Pacific Plate which moves west, and the plate The Indo-Australians are moving northward, as well as the microplate, the Philippine Plate [1].

Based on plate tectonic analysis [2], it is believed that Sulawesi Island is an island built by masses from Sundaland (Western Indonesia) and masses from Australia and oceanic masses that were originally located between Sundaland and Australia before both collided. Even now, in South Sulawesi and West Sulawesi there are believed to be pre-Tertiary micro continents from Australia that infiltrate as alleged in the Gorontalo Basin.

Seismic tomography is a method to describe the subsurface condition using seismic data recorded on the earth surface. Tomography is a special technique that can be used to get the contents of an object with a solid object without cutting or slicing it. It is performed by taking measurements outside the object from various directions to make projections, then reconstruct [3]. Most seismic tomography is performed using waveform data from earthquakes occurring in a region and recorded on some seismograph equipment networks. For areas with high seismicity, this method is good enough to provide information about the subsurface structure of the earth. For areas that are aseismic this method is difficult to implement because in its implementation is very dependent on the earthquake as a source and seismograph network that record it.

A new method of tomography was developed by using ambient noise signals as the main ingredient [4]. Seismic noise generating sources do not depend on the presence of earthquakes and can be recorded whenever and wherever. Based on previous 
studies [5] [6], this method proved reliable in obtaining superficial information under the surface of the earth. This method has also been developed both experimentally [7][8] and theoretically [9][10]. This research has been conducted in various parts of the world such as California, USA [11], South Korea [12], Tibet [13], Europe [14], New Zeeland [15], Australia [16], several locations in Indonesia, including Lake Toba [17], Central Java [18], the Jakarta Basin [19], the western part of East Java [20], and East Java and Bali [21] and several other areas. Ambient noise is an elastic wave that travels through the earth and it is not generated by earthquakes or explosions [22]. Ambient noise is often overlooked because it is not impulsive. These signals are usually discarded or not taken into account in seismic data analysis. However, a new method is able to prove that ambient noise signals can be useful to provide information about subsurface conditions. By using ambient noise tomography, the resolution of tomographic images is no longer dependent on earthquake occurrence but depends only on the distribution of existing seismograph networks.

In seismology, there are two types of signals generated from random wave fields. First, seismic coda results from multiple scattering of seismic waves on a small scale inhomogene [23]. Second is ambient seismic noise that does not depend on earthquakes and can be recorded anytime and anywhere. Ambient seismic noise in short periods ( $\mathrm{T}<20$ seconds) or commonly referred to as microseism is considered to be related to the interaction of ocean waves and ocean floor near the coastline. The peak of microseism is in the period of 10-20 seconds (primary) and 5-10 seconds (secondary)[24].

Rayleigh wave tomography that utilizes earthquake waveforms is only able to describe perturbation with periods over 20 seconds while the period below 20 seconds will be attenuated before it could be recorded by a seismograph. The ambient noise tomography is able to describe the velocity of Rayleigh waves with periods under $20 \mathrm{~s}$, so that it could illustrate the shallow structures of the Earth's crust and the upper mantle [25].

\section{METHODS}

\subsection{Data}

In this study the study area was on Sulawesi Island as seen in Figure 1, whose station network was limited to coordinates $-6.5^{\circ}-2^{\circ}$ latitude and $117.83^{\circ}-125.5^{\circ}$ longitude. The research data in this study were the waveform data of vertical component of broadband seismometer from 25 Indonesian network station Tsunami Early Warning System (INA TEWS) BMKG spread in Sulawesi Island from July 2016 to December 2017.

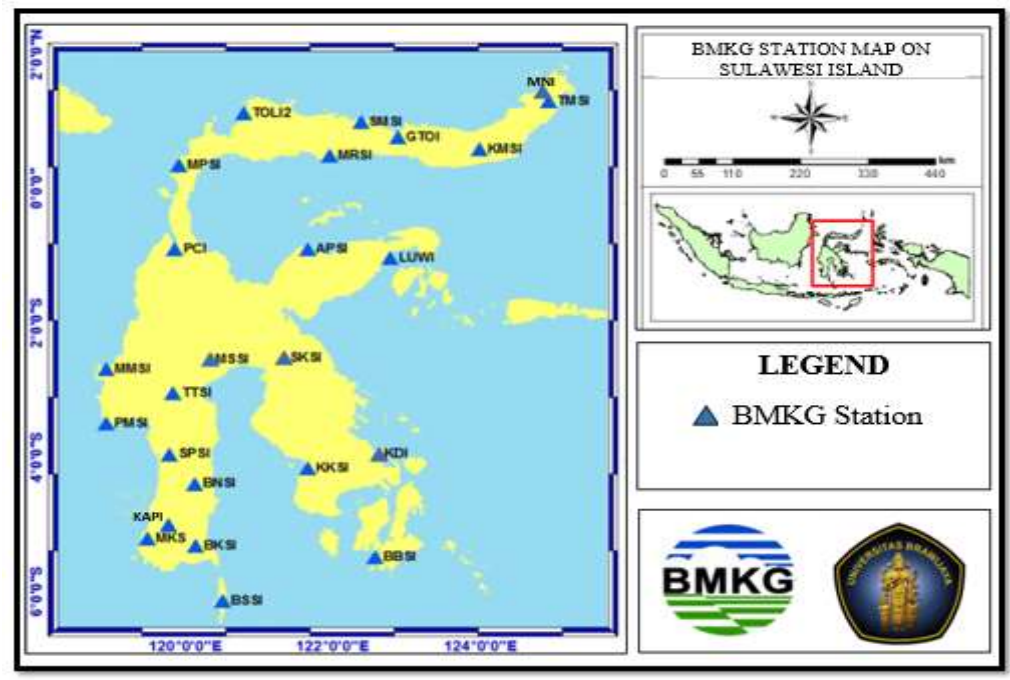

Figure 1: BMKG network stations spread in Sulawesi Island

We followed the steps taken by [26] and [27] in processing of the ambient seismic noise signal data to obtain maps of Rayleigh wave group velocity. In general, the steps of conducting research were divided into several parts, namely single data preparation, cross correlation and stacking, cross correlogram analysis, measurement of dispersion curves, velocity tomography and the last was the interpretation of research results.

\subsection{Single Data Preparation}

The data needed in processing data in this study is noise data so that all recorded events must be removed. With the hope that the final output of this process is a clean signal from the event, both if analyzed in the time domain or frequency domain. To achieve this, several signal processing such as instrument correction, remove mean, remove trend, band pass filtering, temporal normalization, and spectral whitening were performed.

Remove mean aims to return the signal position at zero-mean by removing the mean while the remove trend aims to suppress the frequency increase coming from outside influences. Then bandpass filtering was applied on each day data segment using multiple connecting period bands. Furthermore, instrument correction was carried out because the seismometers distributed on the island of Sulawesi are of different types, so they have different reactions to ground motion. This aims to get pure ground 
motion data. Ground motion can be in the form of ground dispalacement, ground velocity, and ground accelaration. In this study instrument correction was carried out on all data based on polish and zeros values by applying deconvolution.

Temporal normalization was carried out to reduce the effects of earthquake cross correlation, instrument irregularity, and non-stationary noise sources near the station. Temporal normalization is a mandatory procedure if an area has a high level of seismicity. It was explained several methods of normalizing time domains namely one bit normalization, clipped waveform normalization, Atomated event detection and removal normalization, Absolute Running mean normalization and Water level normalization. Among the methods introduced, the one-bit nomination method is the fastest and easiest method to implement. This method replaces all the positive amplitude of the waveform to 1 and the negative amplitude to -1 . In this study, one bit normalization method was chosen [26].

After normalization in the time domain, normalization in the fermentation domain was also applied or commonly called spectral whitening. Spectral whitening was conducted to homogenize signals in the frequency domain which serves to flatten the frequency magnitude in the bandpass filter frequency range.

\subsection{Crosscorrelation and Stacking}

Crosscorrelation and stacking were processed after all single steps of data preparation were carried out. Crosscorrelation was carried out on all possible pairs of stations with the following formula as Equation 1:

$$
\text { Number of pairs }=n(n-1) / 2
$$

with $n$ is the number of stations.

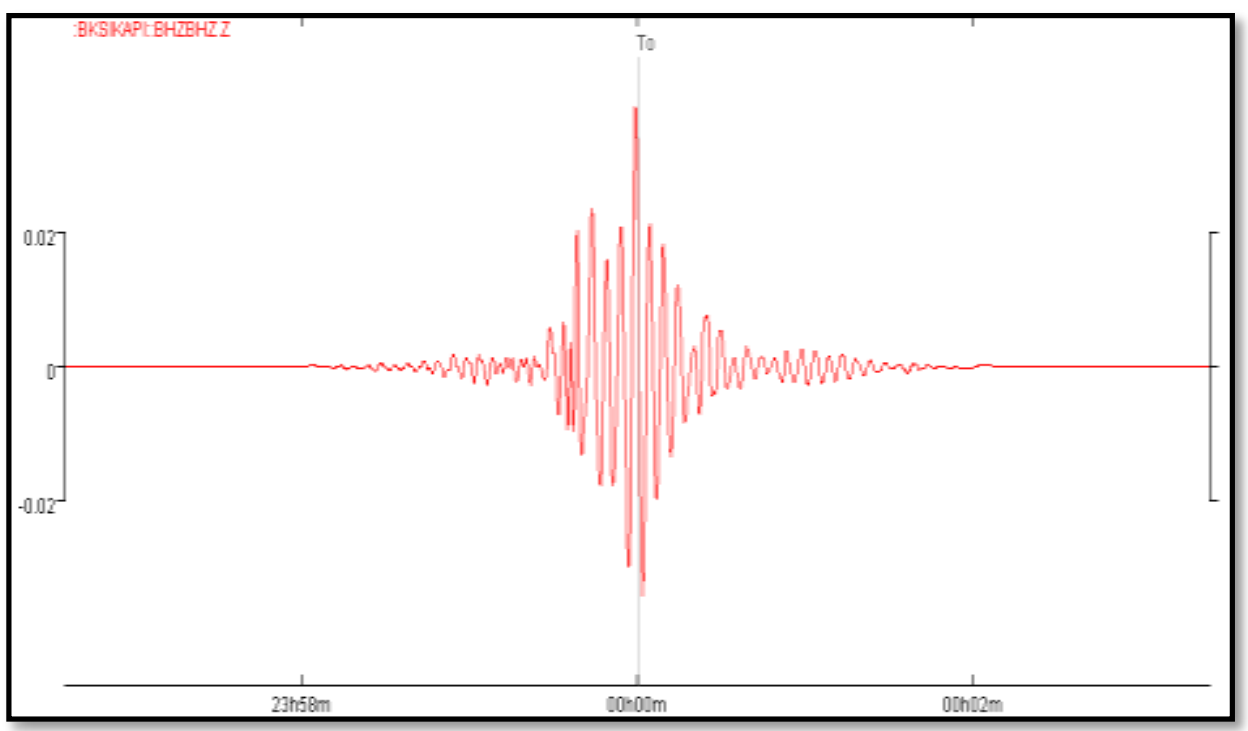

Figure 2: The crosscorrelation results of seismic noise data between BKSI-KAPI stations.

In the crosscorrelation phase, the seismogram used in this process was a vertical component $(\mathrm{Z})$, this was done because the Rayleigh wave is a surface wave that is more visible in the vertical component $(Z)$. The number of pairs of stations that could be crosscorrelation in this study are 196 pairs. The process at this stage used the Python program with the name Corr_days.py which was a program package that calculates cross correlation with one run. The stacking signal was performed by Gaussian Bandpass Filter operation with a period of 10-20 s. Result of crosscorrelation is showed as in Figure 2.

\subsection{Cross Correlogram Analysis and Measurement of Dispersion Curves}

Analysis of cross correlogram was generally performed to determine whether the results of cross correlation are of good quality or not. The analysis was conducted by making crosscoreelation curves on the distance between stations and time in several different periods of time. Based on the results of cross correlogram analysis it iwas estimated that the wave velocity ranges from $1.14 \mathrm{~km} / \mathrm{s}-4.22 \mathrm{~km} / \mathrm{s}$ with an average speed of around $3.25 \mathrm{~km} / \mathrm{s}$.

The measurement of the dispersion curve used a program package from Herrmann (2013) with the name of the do_mft program. This program is a GUI that can be used to extract the dispersion of group speed and phase velocity from the empirical surface wave Green function (EGF) or crosscorrelation function (CF) of ambient noise. Dispersion analysis is based on imaging analysis techniques [28][29], which automatically tracing dispersion curves on group velocity and phase images over a period of time.

In this study Multiple Filtering Technique [30] was applied to each Green function to obtain the spectrogram of each group velocity dispersion. This was performed to isolate the fundamental Rayleigh wave mode of the vertical component by picking on the envelope peaks. 
Some things that need to be considered in this processing are the selection of period ranges, window speed ranges, gamma values, and filters to get the optimal window and dispersion curve resolution. In this research, a window speed range of $1.0-5.0 \mathrm{~km} / \mathrm{s}$ was used. This determination is based on an initial velocity model analysis that the average velocity is estimated to be around $3 \mathrm{~km} / \mathrm{s}$. Figure 3 is an example of the spectrogram measurement of the SPSI-KAPI station dispersion curve measurement.

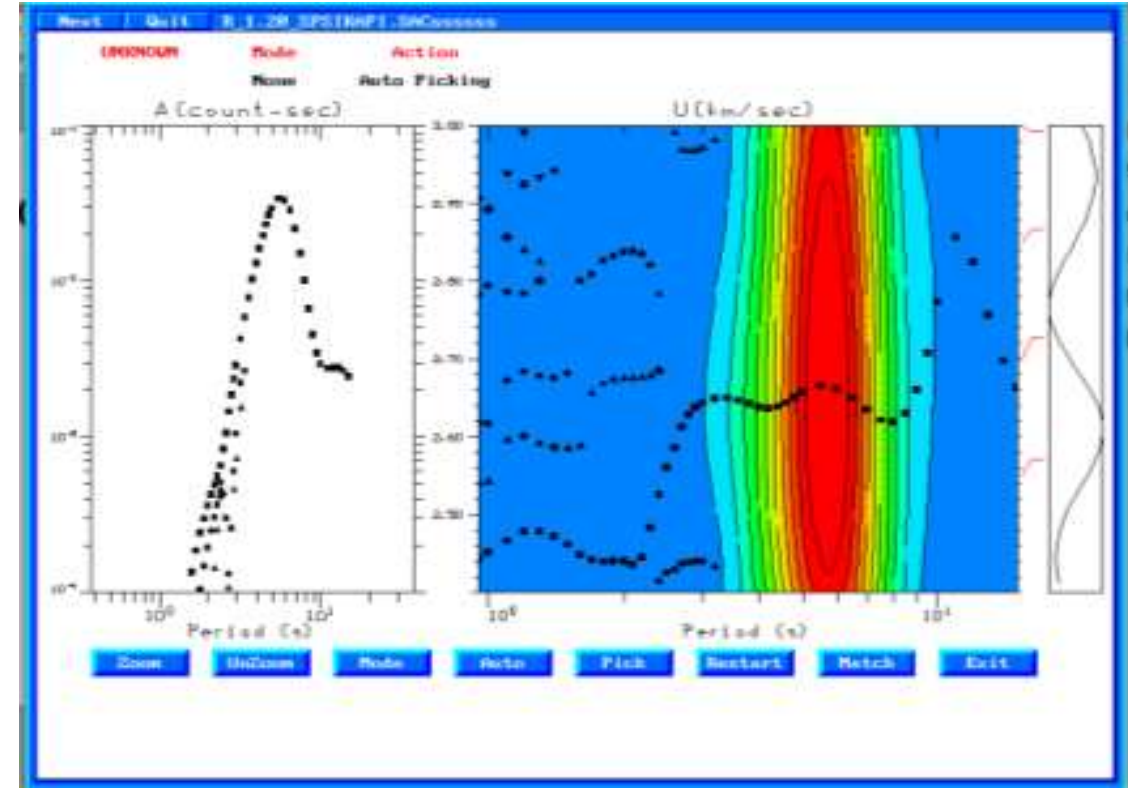

Figure 3: Example of the spectrogram measurement of the SPSI-KAPI station dispersion curve measurement

\section{RESULTS AND DISCUSSION}

\subsection{Resolution Test}

Before Rayleigh Wave modeling was carried out in the study area using existing observation data, first a resolution test was used which serves to see how well the geometry of the distribution of virtual sources and recipients to the subsurface conditions to be mapped. This could be conducted by making synthesis wave velocity data, adding Gaussian noise, then applying tomography to the synthesis data. The inversion Tomogram will have a different resolution area coverage depending on the spread of the ray. In general, the more raypaths that pass through an area, the higher the resolution. Figure 4 shows the distribution of raypaths for the Sulawesi island region where the number of raypaths obtained is 362 paths.

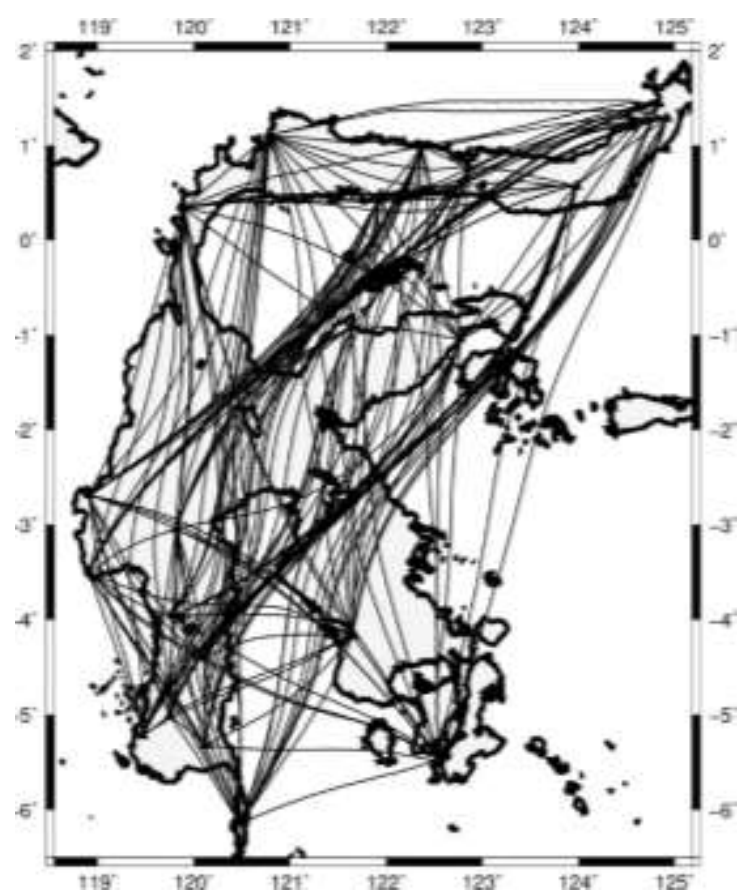

Figure 4: Raypaths distribution of Sulawesi Island at period $7 \mathrm{~s}$.

The resolution test was conducted using a checkerboard test by making a synthetic data model with an initial model in the form of a checkerboard. In this study a chessboard model with cell size of $1^{\circ} \mathrm{x} 1^{\circ}(111 \mathrm{~km} \mathrm{x} 111 \mathrm{~km})$ was made for the $7 \mathrm{~s}$ period with a damping factor of 1000 and a smoothing factor of 1000. The purpose of the damping value was to give the weight of 
the dampers so the value of the solution model was not far from the initial model. Figure 5 is a checkerboard model test and recovery model results for period $7 \mathrm{~s}$ with trace amounts of wave 362 paths.

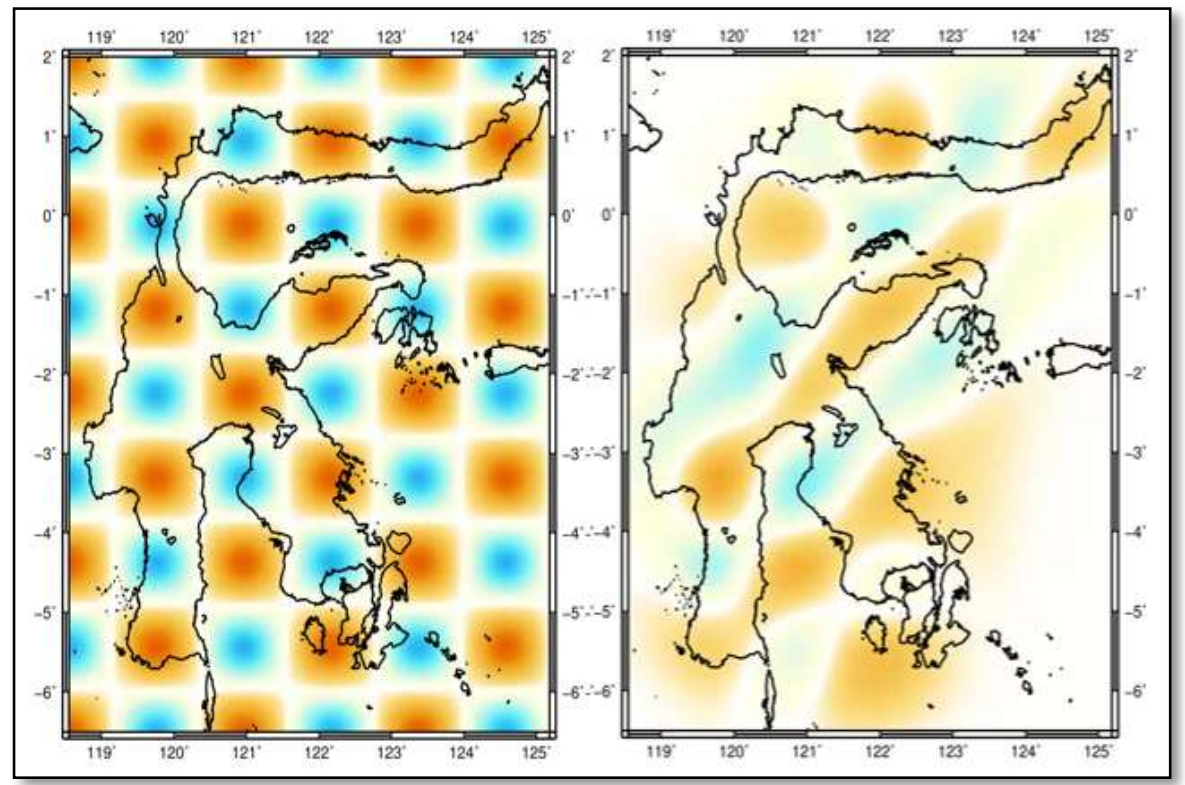

Figure 5: Checkerboard test and model selection results at period $7 \mathrm{~s}$

\subsection{Period $5 \mathrm{~s}$}

The Rayleigh wave velocity map in period $5 \mathrm{~s}$ (figure 6) is sensitive to the upper crust with a depth of up to $8 \mathrm{~km}$ [30]. Overall, the tomogram in figure 6 shows quite good results after being compared with the geological conditions (figure 7). Variations in speed in the study area can be seen quite clearly in several regions.

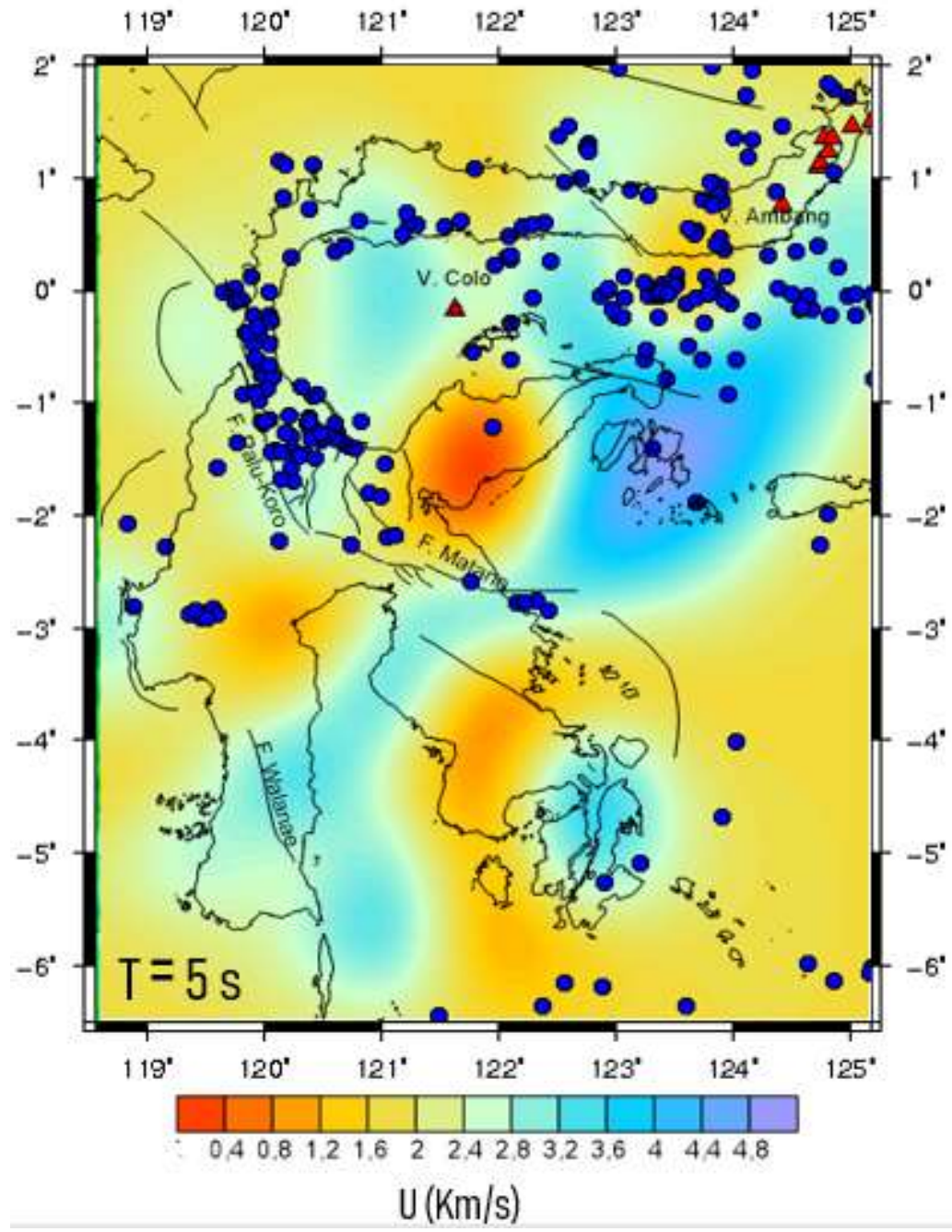

Figure 6: Rayleigh wave group velocity map with period $5 \mathrm{~s}$ in Sulawesi Island (red triangel is volcano, black line is fault and blue circle is eartquake from 2016 to 2018) 
Low speed zones $(0.4-2.4 \mathrm{~km} / \mathrm{s})$ clearly identified on the northern arm of Sulawesi island associated with a series of quaternary volcanoes which generally consist of Paleogene-Quaternary volcanic-plutonic rocks with mesozoic-tertiary-aged sedimentary rocks and metamorphic rocks that dominate a large part of the northern part of the sulawesi arm. This is also in accordance with the study [32] as shown in figure 8 which shows that at a depth of 2-10 km, the shear wave velocity structure (Vs) of the North Arm is very low (1.7-3.5 km/s) and generally homogeneous.

Rows of volcanoes in the northern arm region of Sulawesi are seen at low speed zone boundaries and high speed zones. This is in accordance with the theory that spatially low speed regions can be explained by several parameters, such as rocks that are soft, have low density, contain fluid, and have high temperatures.

Quaternary volcanoes that dominate the island of Sulawesi are composed of quarterly volcanic rocks that have a loose, decomposed, yet well-compiled nature. This condition causes a low speed of seismic waves to pass through it. When there is a thrust from below that causes a volcano to occur, it automatically has a destruction zone or a weak zone associated with a low anomaly next to it. This condition can be the reason why the volcanic sequence in the northern arm region of Sulawesi Island is at the boundary between the zone of low speed anomalies and high speed anomalies. This condition also applies to the geological features of normal faults.

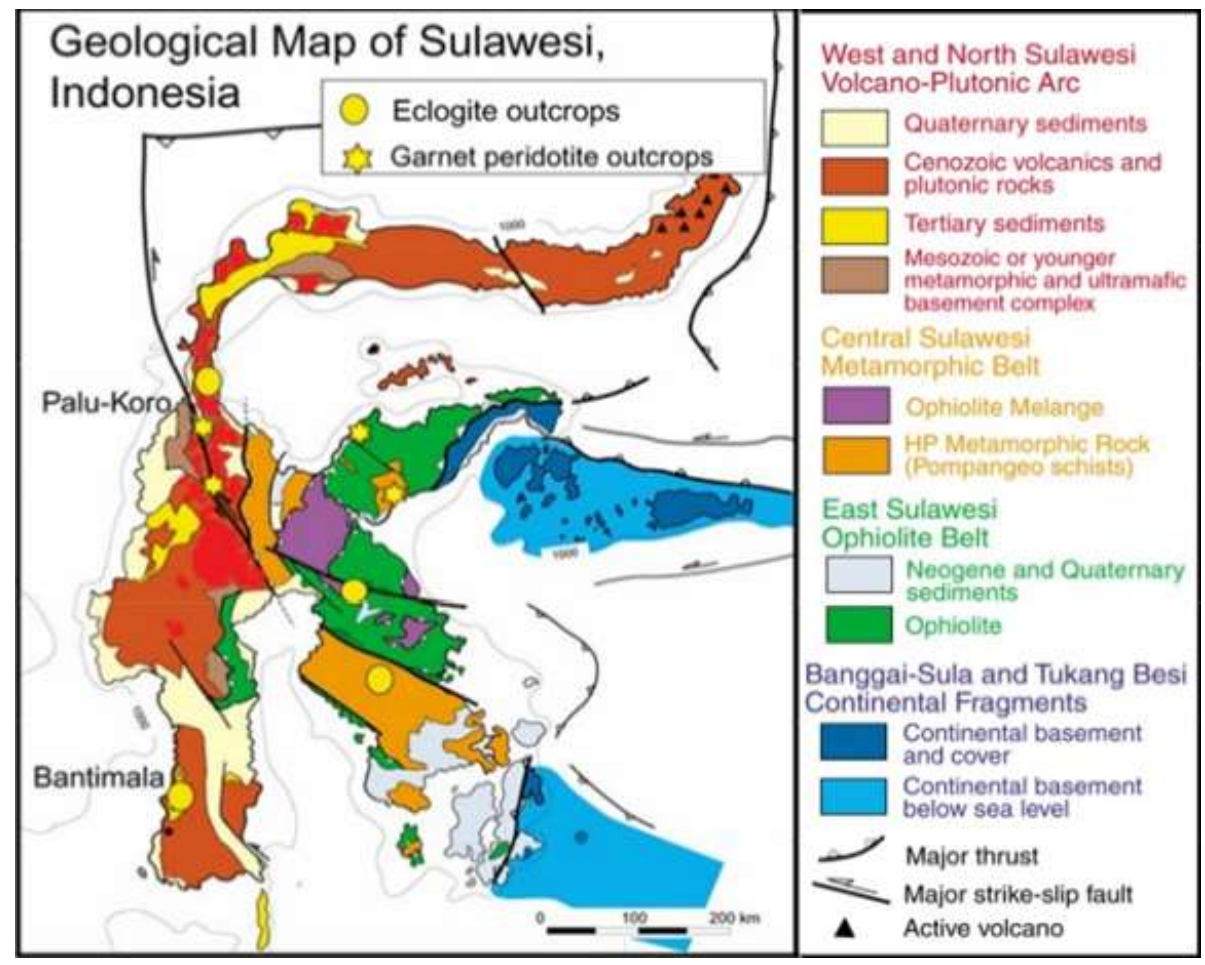

Figure 7: Simplified geological map of Sulawesi (Hall and Wilson, 2000)

The central Sulawesi region is generally in an area that has a very low Rayleigh Wave velocity especially in the eastern arm of Sulawesi Island and rises eastward to the Banggai Islands region. This condition is supported by the Raypath distribution in the Sulawesi region in the $5 \mathrm{~s}$ period as shown in (figure 9) where the area not passed by the raypath is indicated to have sufficient deep sediment thickness. This is in accordance with the fermat principle where the wave will spread from one point to another through the shortest path of its propagation time. Thus if the wave passes through a medium that has a variation in the speed of seismic waves, then the wave will tend through high speed zones and avoid low speed zones [33]. In the central region of Sulawesi the koro hammer faults are seen stretching between the low speed zone and the high speed zone. 


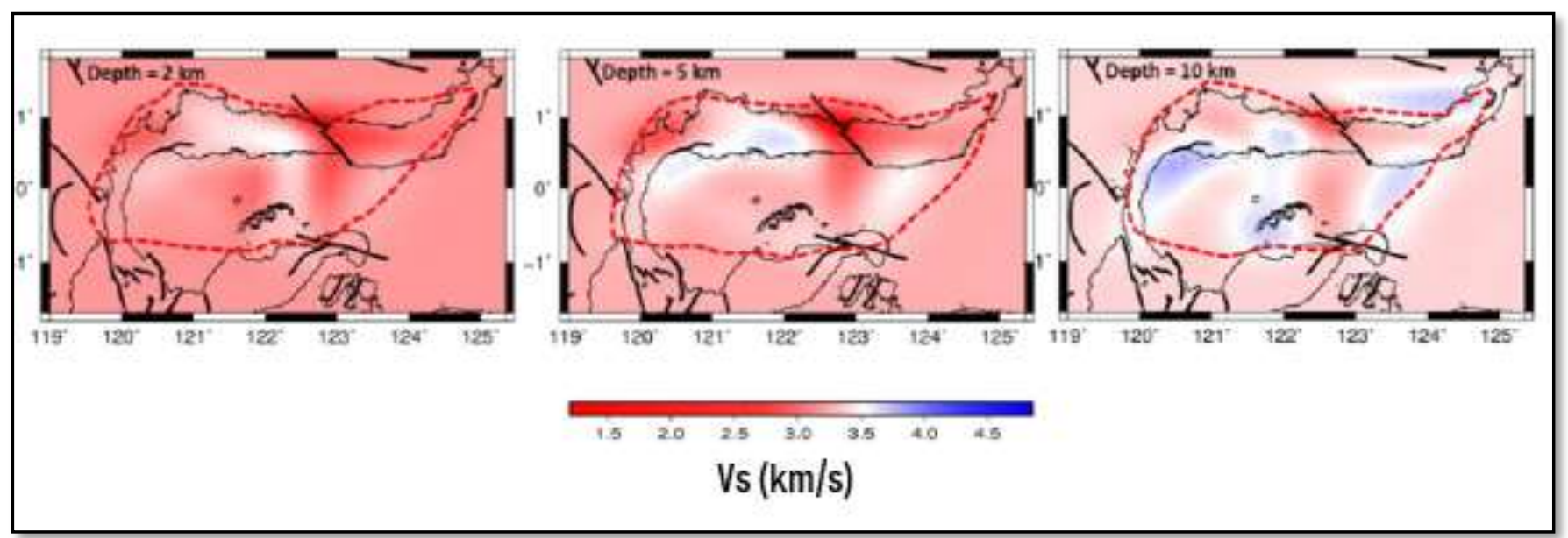

Figure 8: Shear wave velocity structure (Vs) of the North Arm at a depth of 2-10 km (Awaliah, 2018)

The South arm region of Sulawesi island the speed of the Rayleigh wave group also degrades from high to low starting from the south to the north. Sedimentary rocks dominate most of the South Sulawesi Arm, especially along the coast and in the middle of this arm [34]. The speed value increases northeast towards the southeast arm of Sulawesi Island. In the Southeast arm region the speed value varies where the velocity value in the southeastern arm is of high value and low value in the southern region. The high speed zone began to return high in the Tukang Besi archipelago.

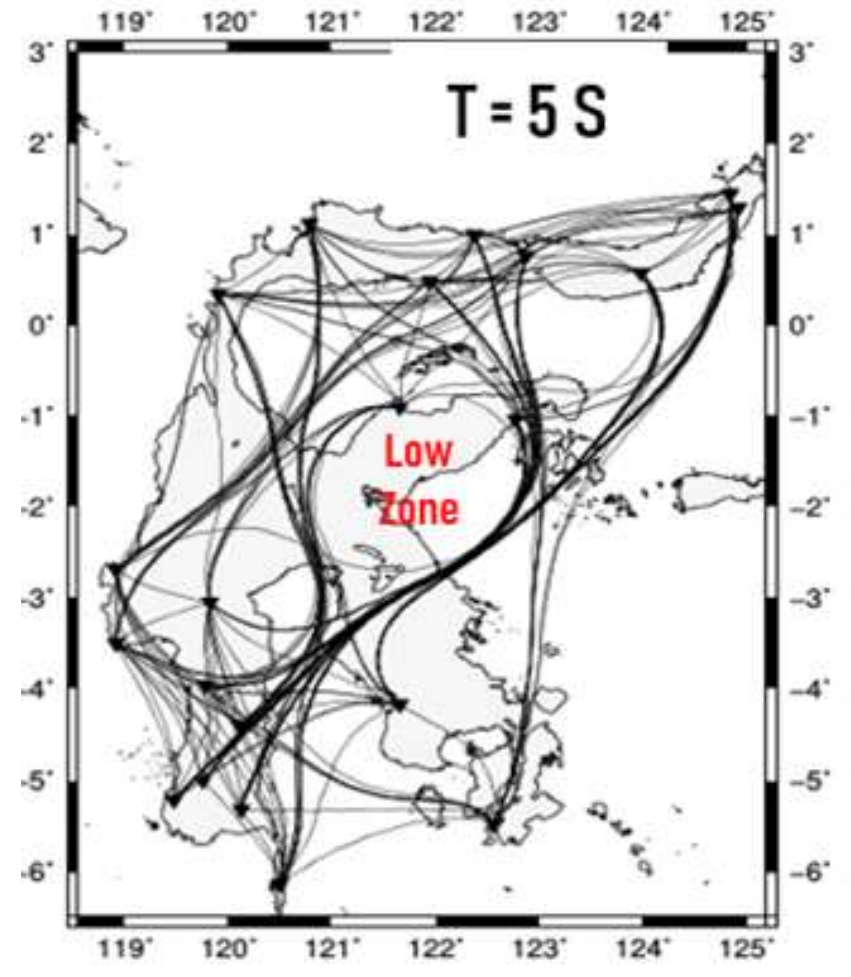

Figure 9: Raypath distribution in the Sulawesi Island at period $5 \mathrm{~s}$

To validate the results of tomography, we also compared them with Complete Bouger Anomaly data (figure 10) obtained from the International Gravimetric Bureau. From these data show that the zone with a complete value of low bouger anomaly is associated with a zone that has a low Rayleigh wave velocity as well as a zone with a complete value of high bougain anomaly associated with a zone that has a high rayleigh wave velocity. Increasing rock density is always accompanied by greater rigidity or compressibility so that the same wave speed will increase. This proves that material that has a high density tends to have high seismic wave velocities and materials that have low density tend to have low seismic wave velocities even though there are some regions that are not in accordance with the bouger anomaly map due to the quality of seismic data not good enough to produce a less suitable Tomogram in some areas of Sulawesi Island. 
International Journal of Advances in Scientific Research and Engineering (ijasre), Vol 5 (1), January-2019

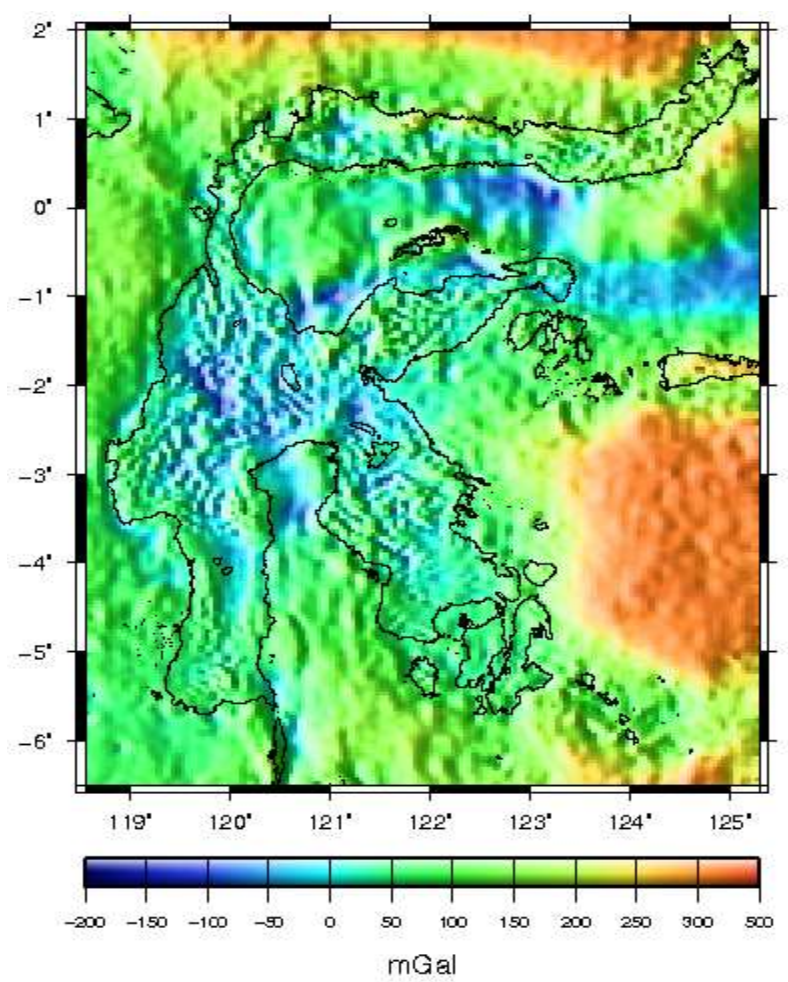

Figure 10: Complete Bouger Anomaly map obtained from data of the International Gravimetric Bureau

\subsection{Period $12 \mathrm{~s}$}

In contrast to the period $5 \mathrm{~s}$ Tomogram where the island area of Sulawesi is dominated by low seismic wave speeds (0.4$2.4 \mathrm{~km} / \mathrm{s}$ ), the results of the $12 \mathrm{~s}$ tomogram as showed in figure 11 (dominated by high seismic speeds $(2.4-4.8 \mathrm{~km} / \mathrm{s}$ ). This shows that the value of the Rayleigh (U) wave velocity will be higher as the period increases. Rayligh waves are dispersive or waves with different frequencies propagate at different speeds. Rayligh waves with a longer period will arrive earlier and can penetrate deeper into the body of the earth compared to those with smaller periods. Therefore Rayligh waves with long periods are more sensitive to deeper earth structures and vice versa. This is consistent with the theory that older rocks will be in the lower layers while younger rocks will be in the upper layers. The Rayleigh wave velocity map in the $12 \mathrm{~s}$ period is sensitive to the subsurface structure of the earth to a depth of $15 \mathrm{~km}$ [35].

Rayleigh wave velocity is high in the northern arm, south arm and part of the southern southeast arm indicating that the earth's crust becomes more compact as depth increases. Based on the tomogram of the $12 \mathrm{~s}$ period it can be seen that the bay part of Tol has very low seismic speed which indicates that the area has sufficient thick sediment. These results are supported by research [36] in the Morowali waters region where the northern and southern parts of the study area are dominated by sedimentary rock which is quite thick. 


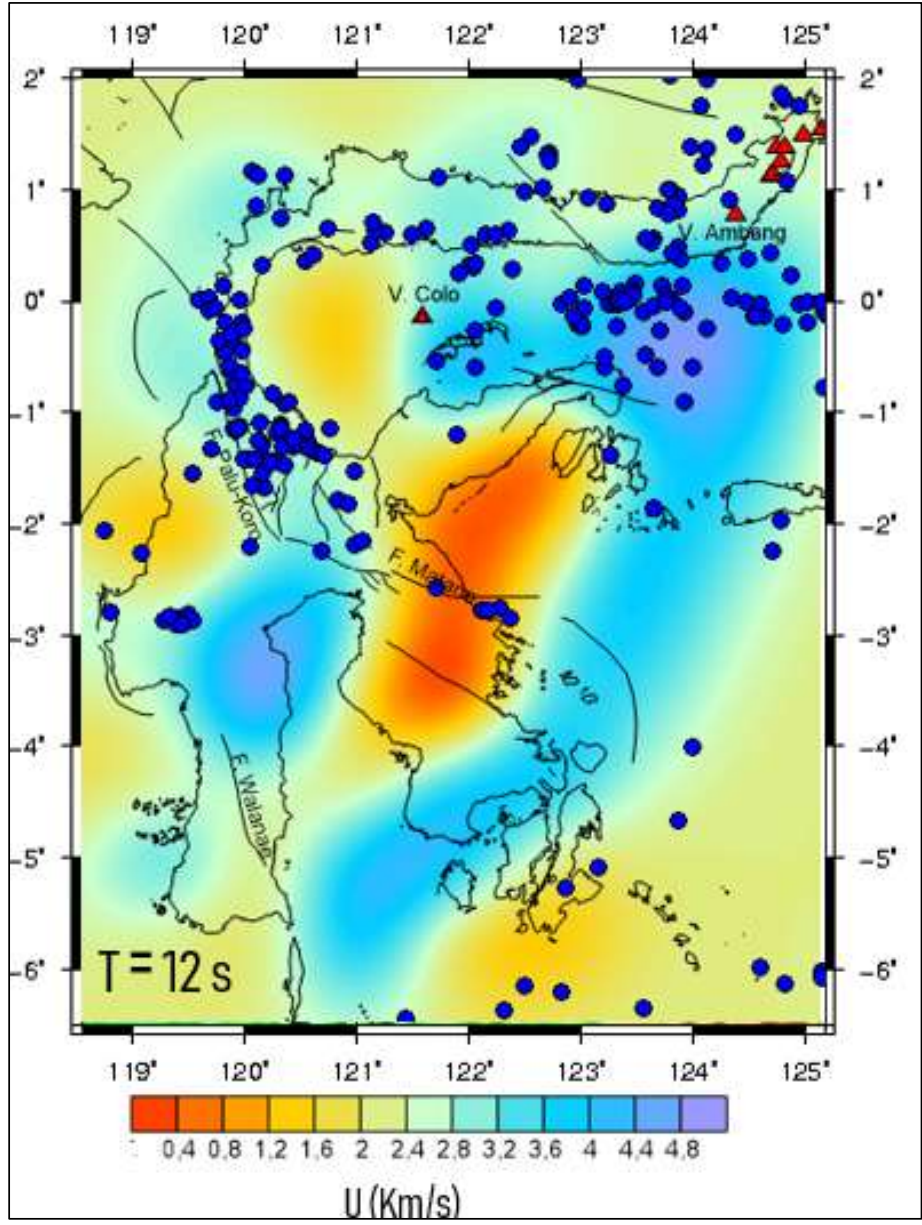

Figure 11: Rayleigh wave group velocity map with period $12 \mathrm{~s}$ in Sulawesi Island (red triangel is volcano, black line is fault and blue circle is eartquake from 2016 to 2018)

\section{CONCLUSION}

The representation of the ANT method on BMKG seismic record data results in the Rayleigh wave group speed tomography for the Sulawesi Island region and its surroundings which generally correlates with the geological conditions of the area. Zones that have high seismic velocity are associated with areas with high Bouger anomalies while zones with which have low seismic velocities are associated with areas with low Bouger anomalies. The tomographic results obtained from this study indicate that the speed value of the Rayleigh wave group (U) in the Sulawesi Island region varies from $0.4 \mathrm{~km} / \mathrm{s}$ to $4.8 \mathrm{~km} / \mathrm{s}$ and in general will be higher as the period increases or in other words the value the velocity of seismic waves obtained increases with increasing depth. The faults in the Sulawesi Island region are clearly identified on the Tomogram which is represented by the boundary between the low speed anomaly zone contrast and the high speed anomaly zone.

\section{ACKNOLEDGEMENT}

We would like to thank the Ministry of Education and Culture of the Republic of Indonesia for scholarship assistance (BU-201703040154). Our thanks to members of Brawijaya Volcano \& Geothermal Laboratory, Physics Department, University of Brawijaya Malang, Meteorological, Climatological and Geophysical Agency Republic of Indonesia (BMKG) that supported the data used in this study. We also thank to all members of Bravo Energeobhas Research Group and PS ESDA (Center for Energy and Natural Resources Studies, University of Brawijaya)

\section{REFERENCES}

[1] Van Leeuwen, T.M. 1994. 25 Years of Mineral Exploration and Discovery in Indonesia. Journal of Geochemical Exploration.

[2] Sukamto, R. 1975b. Tectonic development in Sulawesi and the surrounding area, a synthesis of development based on plate tectonics. IAGI Magazine, (2) 1: 1-13.

[3] Munadi, S.1992. Knowing the LPL Seismic Tomography, No. 3/1992. p.239-248. Lemigas, Indonesia (in Indonesian)

[4] Campillo, Michel. 2004. Ambient Noise Imaging. Institut des scieces de la terre. France

[5] Saphiro N. M., Campillo, M., Stehly, L., dan Ritzwoller, M. H. 2005. High-Resolution Surface-Wave Tomography from Ambient Seismic Noise. Science, Vol 307. 
[6] Porrit, R.W., Miller, M.S., O’Driscoll, L.J., Harris, C.W., Rosmawati, N., da Costa, L.T. 2016. Continent-arc Collision in the Banda arc Imaged by Ambient Noise Tomography. Earth and Planetary Science Letters 449 (2016) 246-258.

[7] Weaver, R. L., dan Lobkis, O. I. 2002. On The Emergence Of The Green's Function In The Correlations Of A Diffuse Field: Pulse-Echo Using Thermal Phonons. Ultrasonics, 40, 435- 439.

[8] Larose, E., A. Derode, M. Campillo, dan M. Fink. 2004. Imaging From One-Bit Correlations Of Wideband Diffuse Wavefields. J. Appl. Phys., 95, $8393-8399$.

[9] Snieder, R. 2004. Extracting The Green's Function From The Correlation Of Coda Waves: A Derivation Based On Stationary Phase. Physical Review. E69 046610.

[10] Wapenaar, K. 2004. Retrieving The Elastodynamic Green's Function Of An Arbitrary Inhomogeneous Medium By Cross Correlation. Physical Review Letters, 93, 254301-1-254301-4.

[11] Yang, Y., \& Ritzwoller M. H. 2008. The Characteristics of Ambient Seismic Noise as a Source for Surface Wave Tomography. Geochemistry, Geophysics, Geosystems, 9(2), Q02008, 18 pages, doi: 10. 1029/2007 GC001814.

[12] Cho, K.H., Hermann, R.B., Ammon, C.J. and Lee, K., 2006. Imaging the crust of Korean Peninsula by surface wave tomography. Bull. Seism. Soc. Am., in press.

[13] Yao, H., van der Hilst, R.D. \& de Hoop, M.V., 2006. Surface-wave tomography in SE Tibet from ambient seismic noise and two-station analysis: I.-Phase velocity maps, Geophys. J. Int., 166, 732-744.

[14] Yang, Y., Ritzwoller, M.H., Levshin, A.L. \& Shapiro, N.M., 2007. Ambient noise Rayleigh wave tomography across Europe, Geophys. J. Int., 168, 259-274.

[15] Lin F., Ritzwoller M.H. dan Shapiro N.M. 2006. Is Ambient Noise Tomography Across Ocean Basins Possible? Geophysics Research Letters, Vol 33

[16] Saygin, E \& Kennet, B. 2008. Ambient Seismic Noise Tomography of Australian Continent Research School of Earth Science. The Australian National University.

[17] Stankiewcs J, Ryberg T, Haberland C, Fauzi, Natawidjaja D. 2010. Lake Toba Volcano Magma Chamber Imaged by Ambient Seismic Noise Tomography. Geophys Res Let 37:L17306. doi:10. 1029/ 2010 GL044211

[18] Zulfakriza Z, Saygin E, Cummins PR, Widiyantoro S, Nugraha AD, Lühr BG, Bodin T. 2014. Upper Crustal Structure of Central Java, Indonesia, from Transdimensional Seismic Ambient Noise Tomography. Geophys J Int 197:630-635

[19] Saygin E, Cummins PR, Cipta A, Hawkins R, Pandhu R, Murjaya J, Masturyono, Irsyam M, Widiyantoro S, Kennett BLN. 2016. Imaging architecture of the Jakarta Basin, Indonesia with transdimensional inversion of seismic noise. Geophys J Int 204(2):918-931

[20] Martha AA, Widiyantoro S, Cummins PR, Saygin E, Masturyono. 2015. Upper Crustal Structure Beneath East Java From Ambient Noise Tomography: a preliminary result. AIP Conf Proc 1658:030009

[21] Martha AA, Widiyantoro S, Cummins PR, Saygin E, Masturyono. 2016. Investigation of Upper Crustal Structure beneath Eastern Java. AIP Conf Proc 1730:020011

[22] Stehly L. et all. 2011. Toward improving ambient noise tomography using simultaneously curvalet denoising filters and SEM simulations of seismic ambient noise. Internal geophysics (Physics of Earth's interior).

[23] Paul, A., Campillo, M., Margerin, L., Larose, E. dan Derode, A. 2005. Empirical Synthesis of Time-Asymmetrical Green Functions from the Correlation of Coda Waves. J.Geophys. Res., 110.

[24] Yang Y., Ritzwoller M.H., Lin F.C., Moschetti M.P., 2008. Stucture of the crust and uppermost mantle bebeath the western United States revealed by ambient noise and earthquake tomography. Journal of Geophysics Research.

[25] Anshori, M., Maryanto, S., Rahman, T.D., Panshori, A. 2018. Ambient Noise Tomography for Determining the Velocity Model of Rayleigh Wave in Java Island, Indonesia. SSRG International Journal of Applied Physics (SSRG-IJAP) - Vol.5 Issue 1 ISSN: 2350 - 0301

[26] Bensen, G.D., Ritzwoller M.H., Barmin M.P., Levshin A.L., Lin F., Moschetti M.P., Shapiro N.M. and Yang Y. 2007. Processing Seismic Ambient Noise Data to Obtain Reliable Broad band surface wave dispersion measurements. Geophysics Jornal International.

[27] Saygin E, Kennett BLN. 2012. Crustal structure of Australia from ambient seismic noise tomography, J Gephys Res 117(B1)

[28] Yao, H. , Xu G., Zhu L.,dan Xiao X., 2005. Mantle Structure from Inter-station Rayleigh Wave Dispersion and Its Tectonic Implication in Western China and Neighboring Regions. Phys. Earth Planet. Inter., 148(1), 39-54.

[29] Yao, H., Gouedard, P., McGuire, J., Collins, J. dan van der Hilst, R.D. (2011). Structure of young East Pacific Rise Lithosphere from Ambient Noise Correlation Analysis of Fundamental-and Higher-mode Scholte Rayleigh Waves. Comptes Rendues Geoscience de l'Académie des Sciences., 343, 571583, doi:10.1016/j.crte.2011.04.004 
[30] Dziewonski A., Bloch S., dan Landisman M. 1969. A Technique For The Analysis Of Transient Seismic Signals. Bulletin of the Seismological Society of America, 59, No. 1, 427-444.

[31] Nicolson H., Curtis A., Baptie B. Dan Galetti E. 2011. Seismic Interferometry and Ambient Noise Tomography in the British Isles. Proceedings of the Geologists' Association.

[32] Awaliah, W. 2018. Identification of 3-D Shear Wave Velocity Structure Beneath Sulawesi Island Using Ambient Noise Tomography Method. Master's Program Thesis, Institut Teknologi Bandung.

[33] Schuster, Arthur. 1904. An Introduction to the Theory of Optics. London: Edward Arnold.

[34] Sukamto, R. 1978. The Structure of Sulawesi in the Light of Plate Tectonics. Proc. Reg. Conf. Geol. Min. Res. SE Asia, 121141.

[35] Liu, Zhikun. Huang, Jinli . Yao, Huajian . 2016. Anisotropic Rayleigh Wave Tomography of Northeast China Using Ambient Seismic Noise. Journal Physics of the Earth and Planetary Interiors 256 (2016) 37-48

[36] Ilahude, D \& Rachmat, B. 2017. Magnetic Anomaly Relationship with Litology on the Geology And Geophysicalmapping in the Water of Morowali, Central Sulawesi. Journal of Marine Geology Vol. 15, No. 1, 